\title{
Complementary foods in Jamaica: viscosity, energy density and feeding practices
}

\author{
Julie Meeks Gardner 1,*, Susan P Walker ${ }^{2}$, Karlene A Gavin ${ }^{2}$ and Ann Ashworth ${ }^{2}$ \\ 'Epidemiology Research Unit, Tropical Medicine Research Institute, University of the West Indies, Mona, Kingston 7 , \\ Jamaica: ${ }^{2}$ London School of Hygiene \& Tropical Medicine, Keppel Street, London WC1E 7HT, UK
}

Submitted 21 August 2000: Accepted 6 March 2001

\begin{abstract}
Objectives: To develop and validate a field method for measuring the viscosity of small quantities of weaning porridges, to measure the viscosity and energy density of porridges fed in urban and rural environments, and to relate the findings to ingredients used and feeding practices.

Design: A new method for determining the viscosity of homogeneous, semi-solid weaning foods was developed. The viscosity and energy density of porridges fed to young children were measured, ingredients obtained by recall, and caregiver feeding behaviours observed.

Setting: One urban and one rural community in Jamaica.

Subjects: A purposive random sample of 70 children aged 3 to 14 months.

Results: Most children (80\%) were fed porridges with medium viscosity (1700$2900 \mathrm{mPas}$ ) or thicker. The mean energy density was $3.18 \pm 0.92 \mathrm{~kJ} \mathrm{~g}^{-1}$. Energy density was only moderately related to viscosity, being higher only in porridges $>4000 \mathrm{mPas}$ (analysis of variance (ANOVA), $P<0.05$ ). Energy density was correlated $(P<0.05)$ with the amounts of sugar $(r=0.28)$ and milk powder $(r=$ $0.24)$ used. Viscosity and energy density were lower in porridges fed by bottle than in those fed by spoon. Anthropometric status (weight-for-length and weight-for-age) was positively correlated with energy density of the porridge but not to the encouragement or persistence of the caregiver.

Conclusions: Porridges of adequate energy density were prepared by caregivers in Jamaica without raising viscosity to levels that might constrain intakes. Improvements in porridge preparation and more varied weaning diets may have contributed to the decline in undernutrition in Jamaica.
\end{abstract}

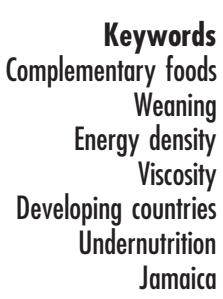

Growth faltering is common among young children in developing countries, affecting as many as 33\% of all children under 5 years of age ${ }^{1}$. A major contributing factor is thought to be the low energy and nutrient density of complementary foods that are fed during the weaning period $^{2}$. Gruels or porridges are a particular problem because they are made from staples with a high content of starch which, when cooked with water, gelatinises and becomes highly viscous. Considerable amounts of water are commonly added to produce a low-viscosity porridge, but this dilutes the nutritional value ${ }^{3}$. Consequently some nutrition intervention programmes promote the use of amylase-rich flours to reduce viscosity while maintaining nutrient density, but their effectiveness and feasibility at the household level have been questioned ${ }^{2,3}$.

In 1995, the World Health Organization (WHO) and the United Nations Children's Fund (UNICEF) jointly convened an expert consultation to consider complementary feeding of infants and young children ${ }^{4}$. One objective was to recommend areas of research that would help answer unresolved programmatic issues. Two of the areas identified were to validate new methods for estimating viscosity in the field, and to measure viscosity and energy density of traditional gruels in representative households in children of different ages, with reference to ingredients used, mode of preparation and feeding. These research areas form the basis for the investigations described in this paper.

In Jamaica, cornmeal (maize) porridge is the traditional complementary food for young children. The specific objectives of our study were to develop and validate a field method for measuring the viscosity of small quantities of home-prepared weaning porridges, to measure the viscosity and energy density of porridges fed to infants at different ages (3-14 months) in urban and rural environments, and to relate the findings to ingredients used and feeding modes. Considering the increasing 
importance attached to caregiver behaviours ${ }^{5,6}$, a further objective was to investigate the feeding styles and types of encouragement given to young children at mealtimes through structured observations.

\section{Subjects and methods}

\section{Development and validation of a field method for measuring the viscosity of gruels}

An attempt was made to measure viscosity by measuring the rate of flow of porridge through a $20 \mathrm{ml}$ graduated pipette that had been modified by cutting off the tip to increase the flow rate. Plastic pipettes were used at first and then specially made glass pipettes were substituted, which had the advantage of producing a smoother flow rate. These pipettes were made from lengths of ordinary glass tubing $24 \mathrm{~cm}$ long and $1 \mathrm{~cm}$ internal diameter, with one end elongated to form a tip. Marks were etched 2, 2

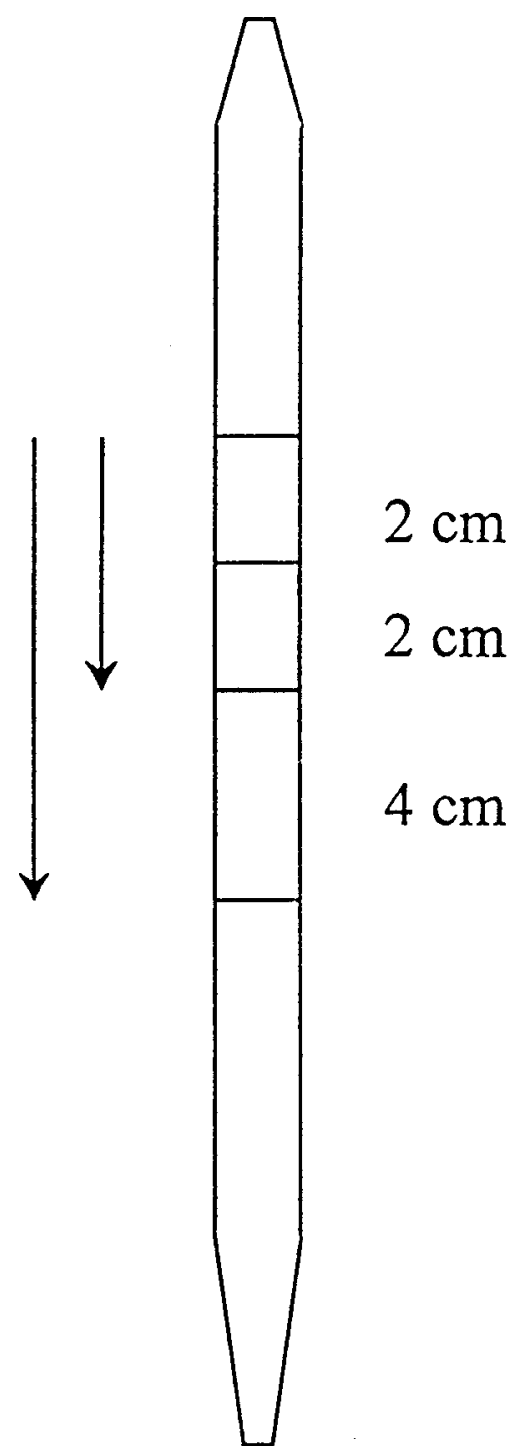

Fig. 1 Pipette used for determination of viscosity and $4 \mathrm{~cm}$ apart (Fig. 1) and the rate of flow between two marks was timed with a stopwatch. For thinner porridges, flow was timed over $4 \mathrm{~cm}$ twice, and for thicker porridges over $2 \mathrm{~cm}$ twice. The mean of each pair of measurements was used for the analyses.

\section{Calibration}

The flow rate versus viscosity relationship was determined for two glass pipettes separately and calibration graphs were produced for each. The temperature range of the porridges was maintained between 50 and $55^{\circ} \mathrm{C}$ for all measurements. Viscosity was measured with a Viscotester VTO4 (Rion, Tokyo), and all measurements were made on the middle scale using rotor number 1 . Porridges with viscosity $>4000 \mathrm{mPa}$ s did not flow down the pipette and were recorded as greater than $4000 \mathrm{mPa}$ s. These porridges were thick and easily heaped. Porridges with viscosity $<500 \mathrm{mPa}$ s flowed so rapidly that the rate was difficult to time and these were recorded as less than $500 \mathrm{mPa}$.

\section{Reproducibility}

When repeated measurements were made within 2 min, i.e. before the porridge cooled, the results were identical, signifying that the flow rate was reproducible if repeated quickly. In order to establish inter-observer reliability, two researchers independently measured 15 porridges with viscosities ranging from 550 to $4000 \mathrm{mPa}$ (measured with the Viscotester). For the independently measured flow rates of 15 porridges, the Pearson's correlation coefficient was $r=0.99$ and the mean difference in flow rates was $1.9 \mathrm{~s}$, equivalent to approximately $50 \mathrm{mPa}$.

\section{Pre-testing}

Before using the method for the main study, its applicability in the field was tested. The researchers measured the flow rates of porridges given to 20 children in the target age range who lived in neighbourhoods adjacent to the study sites. The volume of sample required and the procedure were acceptable to the mothers.

\section{Investigation of viscosity and energy density of porridges fed at different ages}

\section{Location}

Two poor communities, one urban and one rural, were selected near the capital Kingston. Both had demographic profiles similar to other poor urban and rural communities in Jamaica ${ }^{7}$.

\section{Subjects}

A house-to-house survey was carried out to identify homes with children who were aged 3-14 months and were receiving porridge. These ages represent the range during which children are typically fed porridges in the Caribbean. The aim was to recruit every eligible child until 10 children per age group (3-5, 6-8, 9-11 and 12- 
14 months) were obtained in each area. This number was considered sufficient to reflect the typical range of porridge energy densities and viscosities. In the 3-5 and 6-8 month age groups, all eligible children in both areas were recruited but even so, fewer than 10 per age group were enrolled as not all of the younger children were yet receiving porridge. A total of 70 children were recruited, 38 in the urban community and 32 in the rural community. At the first home visit, an arrangement was made for one of the researchers to return to observe a meal at which the child would be fed porridge, but no mention was made that the composition or consistency of the porridge would be investigated in order to prevent the caretaker from altering her usual method of preparation.

\section{Measurements}

All measurements were carried out by one of two researchers (KG and an assistant), both of whom had postgraduate training in nutrition.

\section{Viscosity}

When the child was about to be fed, the caregiver was asked for a small sample of the porridge. Its flow rate through one of the glass pipettes was measured, and its viscosity determined from the flow rate/viscosity calibration graph.

\section{Energy content}

A $30 \mathrm{ml}$ sample of porridge was collected for laboratory analysis. The samples were dried to constant weight and the gross energy determined in triplicate in a bomb calorimeter (Gallenkamp, UK).

\section{Observation of feeding behaviours}

At the same home visit, the researchers observed the meal being fed to the target child using a structured observation schedule. They noted the duration of the meal, the feeding utensils, who fed the baby, the location of the baby and caregiver during the meal, the number of times food was re-offered after a refusal (as an indication of the caregiver's persistence), the number of verbal and non-verbal encouragements given to the baby to complete the meal, and the number of punishments threatened or given during the meal.

\section{Ingredients used}

The types and amounts of the ingredients used for the porridges were obtained by recall. The researchers inspected the actual household utensils used, and measured the quantities indicated.

\section{Feeding patterns and sociodemographic characteristics}

The observer also interviewed the primary caregiver using a structured questionnaire that included questions on past and present feeding of the target child, opinions about porridge consistency, caregiver characteristics, family structure, and housing.

\section{Anthropometry}

The children's lengths and weights (unclothed except for light underwear) were measured using standard techniques $^{8}$. The measurements were converted into $Z$-scores for length-for-age, weight-for-age and weight-for-length, using the National Center for Health Statistics references?

\section{Data analysis}

For the analyses, the viscosity data were categorised into five groups: $<500 \mathrm{mPas}$ (very thin), 500-1699 $\mathrm{mPas}$ (thin), 1700-2899 mPa s (medium), 2900-4000 mPa s (thick), $>4000 \mathrm{mPas}$ (very thick). Metabolisable energy (ME) was calculated using the formula ${ }^{10}: \mathrm{ME}=(0.95 \times$ $\mathrm{GE})-(1.2 \times \mathrm{P})$, where $\mathrm{GE}=$ gross energy and $\mathrm{P}=$ protein content. Protein content was calculated using food tables according to the quantities of ingredients recalled by the caregiver. Metabolisable energy was used in all analyses. For analyses of associations between energy density and specific ingredients, the quantity of each ingredient used as reported by the caregiver as a proportion of the total porridge prepared $(\mathrm{g} / \mathrm{g})$ was correlated with metabolisable energy.

\section{Ethics}

Signed informed consent was obtained from the child's mother or guardian for the family's participation in the study. The study was approved by the University of the West Indies Ethical Committee.

\section{Results}

\section{General observations and limitations}

The field method to measure viscosity worked well in the homes. The volume of porridge required was small (about $10 \mathrm{ml}$ ) and mothers readily agreed to this amount being taken. A minor logistical problem was that the pipettes had to be washed immediately after the measurement so that the porridge would not dry inside. Not all homes had water available and the researchers had to carry their own supply.

\section{Urban/rural characteristics}

Caregivers in the urban areas reported significantly higher levels of education, and had better water/sanitation facilities than rural caregivers. The other sociodemographic characteristics of the caregivers were similar between the urban and rural areas (Table 1). Only three (4\%) of the primary caregivers, all urban, were not the children's mothers.

\section{Viscosity of porridges}

The viscosities of the porridges sampled are presented in Table 2. Most children in all age groups received porridges 
Table 1 Caretaker characteristics and socio-economic status

\begin{tabular}{|c|c|c|}
\hline & Urban $(n=38)$ & Rural $(n=32)$ \\
\hline Caretaker's age in years (mean, SD) & $27.5,7.1$ & $25.3,6.3$ \\
\hline Mother's parity (mean, SD) & $2.2,1.3$ & $2.7,2.0$ \\
\hline Passed high school exams* $(\%)$ & 23.7 & 6.3 \\
\hline Post-school training (\%) & 61.4 & 59.4 \\
\hline \multicolumn{3}{|l|}{ Working (\%) } \\
\hline Full-time (outside the home) & 15.8 & 15.6 \\
\hline Part-time or at home (not housework) & 31.6 & 21.9 \\
\hline Not working & 52.6 & 62.5 \\
\hline Married or cohabiting (\%) & 47.4 & 37.5 \\
\hline \multicolumn{3}{|l|}{ Occupation (\%) } \\
\hline Highly skilled & 7.9 & 3.1 \\
\hline Skilled & 42.1 & 21.9 \\
\hline Semi-skilled & 26.3 & 21.9 \\
\hline Unskilled/never worked & 23.7 & 53.1 \\
\hline Water/sanitation score (mean, SD)†‡ & $8.9,2.8$ & $5.6,3.6$ \\
\hline Crowding score (people per room) (mean, SD) & $2.5,1.1$ & $2.5,1.3$ \\
\hline Possessions score§ & $3.2,1.1$ & $2.9,1.1$ \\
\hline
\end{tabular}

$>1700 \mathrm{mPa}$ s (i.e. medium, thick or very thick). There were no significant differences in porridge viscosity by age group, gender or area of residence.

\section{Energy content of porridges}

Energy densities ranged from 1.70 to $7.31 \mathrm{~kJ} \mathrm{~g}^{-1}$ ( 40.6 to $174.5 \mathrm{kcal} / 100 \mathrm{~g}$ ) (Table 2), with a mean of $3.18 \pm$ $0.92 \mathrm{kJg}^{-1}(76.0 \pm 22.0 \mathrm{kcal} / 100 \mathrm{~g})$. There were no significant differences in energy density by age group, gender or area of residence.

\section{Relationship between viscosity and energy density}

The correlation between porridge viscosity and energy density was fairly low but significant (Spearman's rank order correlation $r=0.31 ; P<0.01$ ). This association was due entirely to the greater energy density of the 'very thick' viscosity category (Table 3).

\section{Socio-cultural factors associated with viscosity and energy/mutrient density}

Caregiver's age was negatively associated with energy density (Pearson's $r=-0.34, P<0.05$ ). The other caregiver characteristics and socio-economic indicators were not significantly associated with viscosity or energy density. Mothers who fed their babies by cup were younger than those using a feeding bottle (analysis of covariance (ANCOVA) $P<0.05$, controlling for child's age).

\section{Meal observations}

The meal observation was carried out in the morning, at midday or in the afternoon (between 8.45 a.m. and 4.45 p.m.). The meals lasted between 2 and $22 \mathrm{~min}$, with a mean of $7.9 \mathrm{~min}$ (standard deviation (SD) $4.8 \mathrm{~min}$ ). Most babies (87\%) were fed by their primary caregivers, five (7\%) by other adults, one (1\%) by another child, and three (4\%) fed themselves. All except three babies were held during the meal, and the caregiver sat beside two of these.

Feeding bottles (with the tips of the teats cut off to make a large hole) were used for 32 babies (46\%), and cups or bowls and spoons in 38 cases (54\%). Energy density was significantly lower in porridges fed by bottle than in those fed by spoon (2.82 vs. $3.49 \mathrm{kJg}^{-1}, t$-test, $P<0.01$ ) and viscosities were also lower in porridges fed by bottle (chisquare, $P<0.001$ ). Only three porridges (9\%) fed by bottle were in the very thick category compared with 21 (55\%) of those fed by spoon. Feeding time tended to be shorter when bottles were used $(6.8 \mathrm{vs}$. $8.9 \mathrm{~min}, t$-test, $P=0.06$ ).

The persistence of the caregiver at mealtimes was indicated by the number of times the porridge was reoffered before the feed was terminated. 'Re-offered' was defined as offering again after a child refused food as indicated by, for example, turning away, spitting out food or moving away. The number of times porridge was reoffered was typically once or twice (not re-offered, $n=$ 10; re-offered once, $n=27$; re-offered twice, $n=20$ ), with a few caregivers persisting for three $(n=6)$, four $(n=4)$ or more times ( $n=1$ for five, six, seven and nine times). Verbal encouragement to eat, which usually comprised only one or two encouraging comments, was given by $44 \%$ of caregivers. Additional types of encouragement including 'pretend' and other games were given by $9 \%$ of the caregivers. In only one case were threats issued to the child to complete the meal, and no punishments were observed. There were no significant associations between encouragement or persistence and caregiver's age or education. 
Table 2 Viscosity and energy density of porridges by age group

\begin{tabular}{|c|c|c|c|c|c|c|c|}
\hline \multicolumn{2}{|c|}{$\begin{array}{c}\text { Age } 3-5 \text { months } \\
(n=10)\end{array}$} & \multicolumn{2}{|c|}{$\begin{array}{c}\text { Age } 6-8 \text { months } \\
(n=18)\end{array}$} & \multicolumn{2}{|c|}{$\begin{array}{c}\text { Age } 9-11 \text { months } \\
\quad(n=23)\end{array}$} & \multicolumn{2}{|c|}{$\begin{array}{c}\text { Age } 12-14 \text { months } \\
\quad(n=19)\end{array}$} \\
\hline $\begin{array}{l}\text { Porridge } \\
\text { viscosity } \\
\text { (mPas) }\end{array}$ & $\begin{array}{c}\text { Metabolisable } \\
\text { energy density } \\
\quad\left(\mathrm{kJ} \mathrm{g}^{-1}\right)\end{array}$ & $\begin{array}{l}\text { Porridge } \\
\text { viscosity } \\
\text { (mPas) }\end{array}$ & $\begin{array}{l}\text { Metabolisable } \\
\text { energy density } \\
\quad\left(\mathrm{kJ} \mathrm{g}^{-1}\right)\end{array}$ & $\begin{array}{l}\text { Porridge } \\
\text { viscosity } \\
\text { (mPas) }\end{array}$ & $\begin{array}{c}\text { Metabolisable } \\
\text { energy density } \\
\quad\left(\mathrm{KJ} \mathrm{g}^{-1}\right)\end{array}$ & $\begin{array}{l}\text { Porridge } \\
\text { viscosity } \\
\text { (mPas) }\end{array}$ & $\begin{array}{c}\text { Metabolisable } \\
\text { energy density } \\
\left(\mathrm{kJ} \mathrm{g}^{-1}\right)\end{array}$ \\
\hline$<500$ & 3.08 & 500 & 3.62 & $<500$ & 2.45 & $<500$ & 3.26 \\
\hline$<500$ & 3.31 & 1100 & 3.27 & 500 & 2.32 & 600 & 2.55 \\
\hline 500 & 2.96 & 1400 & 2.69 & 1200 & 3.65 & 1450 & 2.43 \\
\hline 1300 & 2.68 & 1700 & 2.52 & 1350 & 3.08 & 2000 & 5.08 \\
\hline 1750 & 2.51 & 1750 & 4.36 & 1750 & 3.21 & 2300 & 2.24 \\
\hline 2850 & 1.70 & 1750 & 2.45 & 1900 & 2.85 & 2300 & 4.36 \\
\hline 3650 & 3.73 & 2425 & 2.64 & 1900 & 2.33 & 2350 & 2.98 \\
\hline$>4000$ & 3.56 & 2900 & 3.71 & 2000 & 2.81 & 2350 & 2.65 \\
\hline$>4000$ & 2.99 & 2900 & 2.00 & 2000 & 2.11 & 2700 & 3.59 \\
\hline \multirow[t]{15}{*}{$>4000$} & 3.87 & 3300 & 2.16 & 2100 & 2.01 & 2750 & 2.63 \\
\hline & & 3800 & 2.64 & 2300 & 3.13 & 3250 & 3.51 \\
\hline & Mean \pm SD: & $>4000$ & 2.58 & 2700 & 3.63 & 3600 & 2.84 \\
\hline & $3.03 \pm 0.64$ & $>4000$ & 2.58 & 3350 & 2.41 & 3800 & 2.88 \\
\hline & & $>4000$ & 3.47 & 3500 & 2.19 & $>4000$ & 3.67 \\
\hline & & $>4000$ & 6.55 & 3850 & 3.78 & $>4000$ & 2.36 \\
\hline & & $>4000$ & 3.96 & $>4000$ & 3.73 & $>4000$ & 3.80 \\
\hline & & $>4000$ & 2.89 & $>4000$ & 2.01 & $>4000$ & 3.71 \\
\hline & & $>4000$ & 3.62 & $>4000$ & 3.51 & $>4000$ & 3.40 \\
\hline & & & & $>4000$ & 4.48 & $>4000$ & 7.30 \\
\hline & & & Mean \pm SD: & $>4000$ & 3.35 & & \\
\hline & & & $3.22 \pm 1.07$ & $>4000$ & 3.86 & & Mean \pm SD: \\
\hline & & & & $>4000$ & 3.53 & & $3.43 \pm 1.12$ \\
\hline & & & & $>4000$ & 2.91 & & \\
\hline & & & & & $\begin{array}{c}\text { Mean } \pm \text { SD: } \\
3.01 \pm 0.69\end{array}$ & & \\
\hline
\end{tabular}

\section{Porridge ingredients and associations with energy and viscosity}

Most children (70\%) were observed to have porridge made from traditional high-extraction cornmeal. Other staples given included oats (10\%), wheat cereal (7\%), green banana or plantain (7\%) and commercial baby cereal preparations (6\%). All porridges were prepared with the addition of some kind of milk, the most common being whole milk powder (60\%). Infant formula (24\%), skimmed milk powder (7\%), soy-based formula (4\%), liquid cows' milk (1\%) and sweetened condensed milk (3\%) were also used. Most (89\%) of the caregivers added sugar, 21\% added margarine, but none added oil.

Viscosities were similar with or without margarine. The mean energy density was the same $\left(3.2 \mathrm{kJg}^{-1}\right)$ in porridges prepared with or without added margarine.

Table 3 Mean metabolisable energy density by viscosity categories

\begin{tabular}{lcc}
\hline Viscosity category & $\begin{array}{c}\text { Number } \\
\text { of porridges }\end{array}$ & $\begin{array}{c}\text { Mean metabolisable } \\
\text { energy, SD }\left(\mathrm{kJ} \mathrm{g}^{-1}\right)\end{array}$ \\
\hline Very thin $(<500 \mathrm{mPas})$ & 4 & $3.02,0.39$ \\
Thin $(500-1699 \mathrm{mPa} \mathrm{s})$ & 10 & $2.92,0.47$ \\
Medium $(1700-2899 \mathrm{mPas})$ & 21 & $2.94,0.85$ \\
Thick $(2900-4000 \mathrm{mPa})$ & 11 & $2.89,0.68$ \\
Very thick $(>4000 \mathrm{mPas})$ & 24 & $3.67,1.16$ \\
\hline
\end{tabular}

ANOVA, $P<0.05$.
Energy density was correlated with the quantity of sugar (Pearson's $r=0.28, P<0.05$ ) and milk powder or formula used $(r=0.24, P<0.05)$, but not with the quantity of the staple added. (Three cases with liquid cows' milk or sweetened condensed milk were omitted from these correlational analyses.)

\section{Reported porridge preparation and feeding practices}

All children except one (98.6\%) were reported to have been breast-fed, and just over half were still being breastfed at the time of the interview. All babies in the youngest (3-5 months) age group, while only $31 \%$ of those in the oldest age group (12-14 months), were still being breastfed. There was no significant urban/rural difference in the proportion of children still being breast-fed in the different age groups.

Most mothers indicated that the porridge they gave when it was first introduced to the child was thinner than currently fed. Porridges were usually first introduced when the children were 3 to 5 months old $(73 \%$ of caregivers). Caregivers reported that they offered porridge on about half of all days (median 3.5 days per week, range $1-7)$. On the days it was prepared, porridge was usually cooked once (97\%) but fed to the child more often (median 3 times per day, range $1-5$ ). When fed again, 43\% of mothers reheated the porridge and $51 \%$ added water to thin it. In the samples collected, which did not include 
Table 4 Children's anthropometry (Z-scores)

\begin{tabular}{lccccc}
\hline & \multicolumn{2}{c}{ Urban $(n=37)$} & & \multicolumn{2}{c}{ Rural $(n=32)$} \\
\cline { 2 - 3 } & Mean & SD & & Mean & SD \\
\hline Weight-for-height & -0.19 & 1.02 & & 0.26 & 1.07 \\
Weight-for-age* $^{*}$ & -0.52 & 0.88 & & -0.001 & 1.25 \\
Height-for-age & -0.46 & 0.78 & & -0.25 & 1.05 \\
Age (months) & 9.2 & 3.2 & & 9.2 & 3.4 \\
\hline
\end{tabular}

${ }^{*} t$-test, $P<0.05$.

evening or night feeds, the mean energy density was somewhat higher, but not significantly different, for those caregivers who reported they did not add water to thin the reheated porridge compared with those who did. We found a weak association between energy density and time of feeding which approached significance (Pearson's $r=0.21, P<0.10)$. Porridges fed later in the day would include those prepared earlier as well as those prepared at that time.

The caregivers were asked which food items were included in the children's diets. Most (77.5\%) of the children were receiving some meat or fish, and $80 \%$ a staple food (e.g. potato or rice) besides porridge. Many children also received cheese (63\%), fruits (53\%), soup (54\%), vegetables (47\%) and eggs (29\%). Most of these items were introduced between 5 and 7 months of age, and none was said to have been introduced before 3 months of age. Thirty-four per cent of the children were receiving herbal teas and $47 \%$ had commercial sweet drinks.

\section{Antbropometry of the children}

The weight-for-age $Z$-scores of the children in the urban area were significantly lower than those for the children in the rural area (Table 4). Weight-for-length and weight-forage $Z$-scores were significantly associated with energy density of the porridges (Pearson's $r=0.33, P<0.01$ and $r=0.24, P<0.05$, respectively), but length-for-age was not. There were no significant associations between the children's anthropometry and the level of caregiver encouragement or persistence observed. The mean age of the children was the same in the urban and rural areas.

\section{Discussion}

We have developed a reliable field method to measure porridge viscosities ranging from 500 to $4000 \mathrm{mPas}$ at home. During the pilot phase two other methods were attempted, including using the rate of porridge flow on a flat surface and trying to relate porridge density to viscosity, but these were unsuccessful. Although portable viscometers are manufactured, they require large quantities of the material being measured. The advantages of our method are that it requires $<10 \mathrm{ml}$, is acceptable to the mothers and is quickly performed, so that viscosity at the actual eating temperature is measured. The pipette is cheap and simple to make.

The WHO/UNICEF consultation ${ }^{4}$ recommended that data should be collected on the actual viscosity of foods currently given to children in representative households in different environments. In the Jamaican setting there were no differences in viscosity between urban and rural households.

Thick porridges fed by spoon are promoted by the Jamaican Ministry of Health through nutrition rehabilitation clinics and child welfare clinics, as well as intermittent public education programmes. There appears to be a gradual shift away from feeding bottles and towards cups and spoons, as $46 \%$ of the mothers were using bottles compared with some $75 \%$ in $1975^{11}$ and $59 \%$ in $1982^{12}$. Forty-nine per cent of the porridges had viscosities $>2900 \mathrm{mPas}$ (i.e. thick or very thick). We have shown previously that a viscosity of $3000-4000 \mathrm{mPas}$ does not constrain intake ${ }^{13}$. Porridges fed by bottle were of a lower viscosity than those fed by spoon and took less time to feed. Although mothers reported that a thinner consistency is appropriate when porridges are first introduced, we found no association between viscosity and infant age.

The mean energy density of the porridges was $3.18 \mathrm{~kJ} \mathrm{~g}^{-1}$. This is higher than the energy densities of 1$2 \mathrm{kJg}^{-1}$ typically reported for developing countries ${ }^{3,14}$. It is also higher than found previously in Jamaica ${ }^{15}$. Previous studies in Jamaica have described the addition of small amounts of sweetened condensed milk to porridge after cooking, the milk being added as a flavouring ${ }^{16}$. The striking observation in our study is the change to the use of whole milk powder, which has become widely available at relatively low cost in the past decade, and in fact is the best value in terms of energy compared with the other types of milk used. In addition, the use of sweetened condensed milk to feed babies is discouraged by the Ministry of Health. Higher energy densities were associated with greater quantities of sugar and milk powder used in porridge preparation, but not with the amount of the staple, nor whether margarine was added or not. The lack of effect with margarine is probably due to the small amount added (mean $1.6 \mathrm{~g} / 100 \mathrm{~g}$ porridge). The Ministry of Health currently promotes adding sugar and margarine to porridges only to mothers of malnourished children, although adding margarine was promoted to all mothers in the past.

Porridges were first introduced to some children at age 3-5 months, although in this youngest age group studied not all infants identified were receiving porridge. Introduction of porridges at this age (3-5 months) is early compared with current international recommendations of 'about 6 months ${ }^{17}$, although the timing is not dissimilar to the recommendations of the Jamaican Ministry of Health (4-6 months). This pattern is consistent with previous reports on weaning practices in Jamaica and the Caribbean ${ }^{16}$. 
In many cases, the mothers store cooked porridges and feed them later the same day. Approximately half of the mothers reported adding some water when porridges were re-fed. We sampled porridges throughout the day (although not in the evening) so it is likely that the data include porridges prepared earlier and possibly diluted. Those fed for the evening meal may have been diluted further and lower energy density as a result.

There was a weak but significant association between energy density and viscosity. This suggests that the ingredients that raised energy density did so without substantially increasing viscosity. This is consistent with the associations found between energy density and milk and sugar, and no association with the staple. The results indicate that it is possible to have adequate energy density over a range of viscosities, and that in some countries promoting the addition of dried full-cream milk and sugar to porridge may be more feasible initiatives than the promotion of amylase-rich flours. Where milk is not available, adding groundnut paste (peanut butter) is effective in increasing energy and nutrient density.

An energy density of $2.73 \mathrm{~kJ} \mathrm{~g}^{-1}$ has been estimated to meet the requirements of nearly all non-breast-fed infants if the infants are fed at least four times per day ${ }^{2}$. For breastfed infants aged 6-24 months, assuming average intakes of breast milk, the minimum energy density recommended ranges from 1.85 to $3.11 \mathrm{~kJ} \mathrm{~g}^{-1}$ depending on age if fed four times and from 2.48 to $4.12 \mathrm{~kJ} \mathrm{~g}^{-1}$ if fed three times daily. Thus the energy density of most of the porridges measured in this study would meet the requirements of the infants except perhaps in the oldest age group. However, the older children are more likely to be also eating significant amounts of other family foods.

Of the caregiver characteristics examined, only age was significantly associated with energy density, with younger mothers feeding more energy-dense porridge. This may be just a chance finding, or younger mothers may be more willing to follow Ministry of Health recommendations. This is also suggested by the finding that younger mothers were more likely to feed with a cup than with a feeding bottle.

The meal observations showed that most children were assisted to eat. There was, however, little encouragement and mothers showed little persistence. This laissez-faire style of feeding has been found to be associated with low intakes among infants in other countries ${ }^{18,19}$. Although there has been some decline in the use of feeding bottles, they were still used by $46 \%$ of caregivers despite promotion of 'cup and spoon' by the health services. Spoon-feeding is messier and takes longer, which may act as a deterrent. Further work is needed to understand why mothers prefer feeding bottles.

In Jamaica the prevalence of undernutrition (weight-forage $<-2$ SD) in children under 5 years has fallen from $14 \%$ in $1985^{20}$ to $6 \%$ in $1996^{21}$. The fact that porridges are more energy-dense than they used to be, and are part of a mixed diet rather than the sole or dominant complementary food, may have contributed to this trend.

In summary, most porridges had energy densities that were higher than we expected. We believe this is due to a modest shift to thicker porridges fed by spoon and a more substantial change in what is fed, namely a shift from small additions of sweetened condensed milk to larger additions of whole milk powder and sugar.

\section{Acknowledgements}

This study was funded by UNICEF, New York. We thank D Grant and A Badaloo for assistance, and the parents of the children for their kind co-operation.

\section{References}

1 United Nations Administrative Committee on Coordination Sub-Committee on Nutrition. 4th Report on The World Nutrition Situation. Geneva: ACC/SCN, 2000.

2 World Health Organization (WHO). Complementary Feeding of Young Children in Developing Countries: A Review of Current Scientific Knowledge. WHO/NUT/98.1. Geneva: WHO, 1998.

3 Ashworth A, Draper A. The Potential of Traditional Technologies for Increasing the Energy Density of Weaning Foods - A Critical Review of Existing Knowledge with Particular Reference to Malting and Fermentation. WHO/CDD/EDP/92.4. Geneva: World Health Organization, 1992.

4 World Health Organization (WHO). Complementary Feeding of Infants and Young Children. Report of a Technical Consultation. WHO/NUT/96.9. Geneva: WHO, 1998.

5 Engle PL, Ricciuti HN. Psychosocial aspects of care and nutrition. Food Nutr. Bull. 1995; 16: 356-77.

6 Engle PL, Menon P, Haddad L. Care and Nutrition: Concepts and Measurement. Washington, DC: International Food Policy Research Unit, 1997.

7 Planning Institute of Jamaica. Economic and Social Survey of Jamaica, 1997. Kingston: Planning Institute of Jamaica, 1998.

8 Lohman TG, Roche AF, Martorell R. Anthropometric Standardization Manual. Champaign, IL: Human Kinetics Books, 1988.

9 Hamill PVV, Drizd TA, Johnson CI, Reed RB, Roche AF. NCHS Growth Curves for Children, Birth-18 years. National Center for Health Statistics, Centers for Disease Control. Series 11, 165. DHEW publication (PHS) 78 1650. Washington, DC: US Government Printing Office, 1978.

10 Miller DS, Payne PR. A ballistic bomb calorimeter. Br. J. Nutr. 1959; 13: 501-8.

11 Fox HC, Gordon E, Peat G, Hall M. Community Nutrition Studies. Kingston: Ministry of Health, 1975.

12 Ashley D, Fox K. Final Report: Infant Feeding patterns in Jamaica 1982. Kingston: Ministry of Health, 1984.

13 Stephenson D, Meeks Gardner J, Walker S, Ashworth A. Weaning food viscosity and energy density: their effects on ad libitum consumption and energy intakes in Jamaican children. Am. J. Clin. Nutr. 1994; 60: 465-9.

14 Brown KH, Dickin KL, Bentley ME, Oni GA, Obasaju VT, Esrey SA, Mebrahtu S, Alade I, Stallings RY. Consumption of weaning foods from fermented cereals in Kwara State, Nigeria. In: Alnwick D, Moses S, Schmidt OG, eds. Improving Child Feeding in Eastern and Southern Africa: Housebold Level Food Technology. Ottawa: IDRC, 1988: 181-97.

15 Hibbert JM. Nutrient and bacterial content of infants' 
bottle feeds, MSc thesis, University of the West Indies, Mona, 1980.

16 King J, Ashworth A. Changes in Infant Feeding Practices in the Caribbean. An Historical Review. London: London School of Hygiene and Tropical Medicine, 1987.

17 United Nations Children's Fund (UNICEF). UNICEF Position on the Duration of Exclusive Breastfeeding. UNICEF Nutrition Section, November 1999.

18 Dettwyler KA. Styles of infant feeding: parental/caretaker control of food consumption in young children. $\mathrm{Am}$. Anthropol. 1989; 91: 696-703.
19 Bentley ME, Black MM, Hurtado E. Child feeding and appetite: what can programmes do? Food Nutr. Bull. 1995; 16: $340-8$.

20 Fox K, Ashley D. Report of a Survey of Health Status of Children less than Ten Years in Jamaica. Kingston: Ministry of Health, 1985.

21 Planning Institute of Jamaica. Jamaica Survey of Living Conditions, 1996. Kingston: Planning Institute of Jamaica, 1997. 